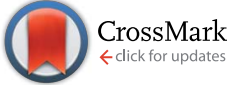

Cite this: Chem. Sci., 2016, 7, 4537

\title{
The role of dynamic ligand exchange in the oxidation chemistry of cerium(III) $\uparrow$
}

\author{
Jerome R. Robinson, Yusen Qiao, Jun Gu, Patrick J. Carroll, Patrick J. Walsh* \\ and Eric J. Schelter*
}

The $C \mathrm{e}^{\mathrm{III} / \mathrm{IV}}$ couple is useful for many applications in organic, inorganic, and materials chemistry. However, attaining a general method to access both oxidations states through reversible solution redox chemistry remains challenging. Herein we report the synthesis, characterization, and oxidation chemistry of the novel Ce/Li REMB heterochiral diastereomer, 1-Ce(het). The solution exchange processes of 1-RE(het) $(\mathrm{RE}=\mathrm{Ce}$ and $\mathrm{Yb})$ were investigated to estimate rates of ligand and cation exchange relevant in homochiral and heterochiral frameworks. A detailed mechanistic investigation following the solution dynamics of $1-\mathrm{Ce}$ (het) revealed reactivity controlled both by ligand reorganization and redistribution processes. Ligand reorganization was responsible for the kinetics associated with the chemical oxidation reaction, whereas ligand redistribution and exchange dictated the isolated products.

Received 18th December 2015

Accepted 22nd March 2016

DOI: $10.1039 / \mathrm{c} 5 \mathrm{sc} 04897 \mathrm{~d}$

www.rsc.org/chemicalscience

Li, $\mathrm{Na}, \mathrm{K}$, and Cs; B = (S)-BINOLate; RE/M/B = 1/3/3). We found

\section{Introduction}

The metal-ligand bonds formed in trivalent rare earth metal (RE) complexes are ionic in nature, and show faster rates of ligand exchange compared to the more covalent metal-ligand bonds found in transition metal systems. ${ }^{1}$ The increased ligand lability can be an advantageous property for applications such as MRI contrast agents, sensors, and catalysts, ${ }^{2}$ however, only if suitable ancillary ligand design strategies are implemented to enforce specific coordination environments and control rates of ligand exchange. ${ }^{2 c, 3}$ Well known methods to control rates of ligand exchange with transition metal and lanthanide complexes include the use of bulky or multidentate ligands. ${ }^{4}$ More challenging, however, is development of general and predictable ligand-based strategies to control redox chemistry with molecular lanthanide complexes. ${ }^{5}$ Among the lanthanides cerium's accessible $4 \mathrm{f}^{1} / 4 \mathrm{f}^{0}$ redox couple has attracted much attention due to its diverse applications in organic, inorganic, and materials chemistry. ${ }^{4 a, 5 e, 6}$ Nonetheless, its applications in solution chemistry could be significantly broadened if a better understanding of the factors that control its redox properties, including ligand reorganization and exchange processes, could be gained.

Recently, we reported an alternative strategy for controlled cerium redox chemistry making use of a heterobimetallic platform, $\left[\mathrm{M}_{3}(\mathrm{THF})_{h}\right]\left[(\text { BINOLate })_{3} \mathrm{RE}\right]$ (Fig. 1; REMB; RE $=\mathrm{Ce}, \mathrm{M}=$

P. Roy and Diana T. Vagelos Laboratories, Department of Chemistry, University of Pennsylvania, Philadelphia, PA 19104, USA. E-mail: pwalsh@sas.upenn.edu; schelter@sas.upenn.edu

$\dagger$ Electronic supplementary information (ESI) available: Experimental details, NMR spectra, electrochemical data, UV-vis data, and crystallographic data (CIF). CCDC 1442465 and 1442466. For ESI and crystallographic data in CIF or other electronic format see DOI: $10.1039 / \mathrm{c} 5 \mathrm{sc} 04897 \mathrm{~d}$ that the properties and oxidation chemistry of $\mathrm{Ce}^{\mathrm{III}}$ were modulated by ligand reorganization. ${ }^{7}$ The ability of the $\mathrm{Ce}^{\mathrm{III}}$ complex to reorganize the ligand framework and coordinate neutral ligands,

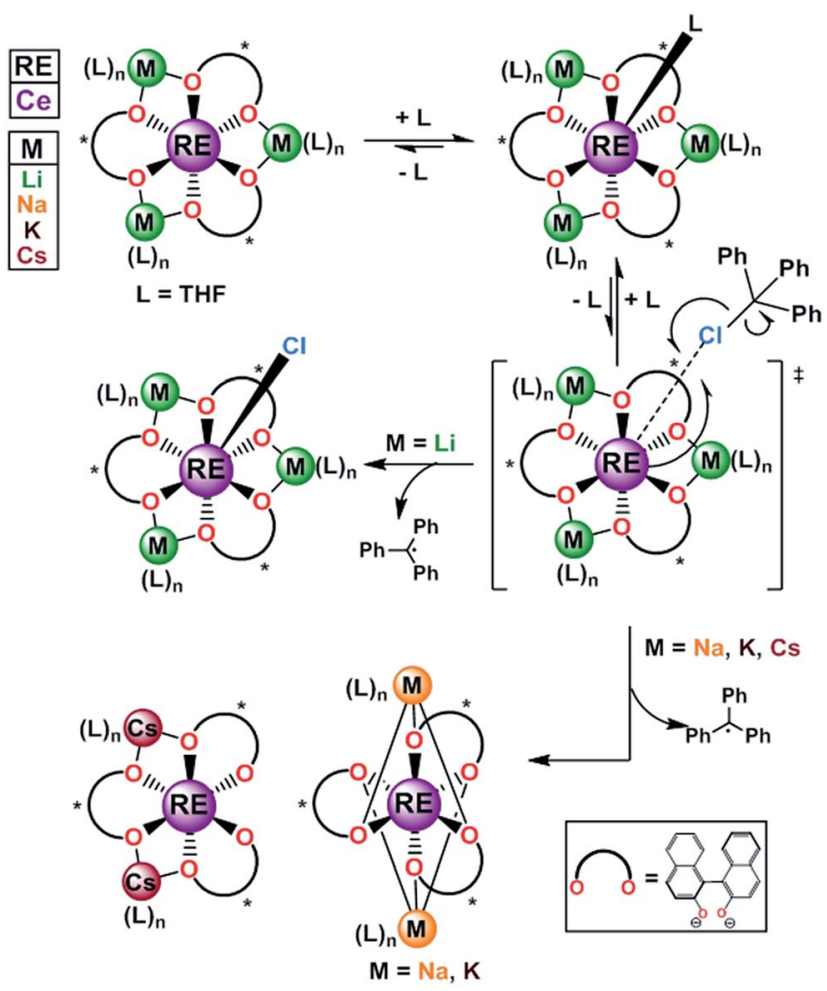

Fig. 1 The homochiral REMB framework, 1-RE(homo) and reactivity with inner sphere oxidant trityl chloride. $R E=$ rare earths; $M=L i, N a, K$, Cs; $B=(S)$-BINOLate; $R E / M / B=1 / 3 / 3$. 
such as THF or TPPO (TPPO = triphenylphosphine oxide) or oxidants was controlled from the secondary coordination sphere through simple choice of the main group metal, $\mathrm{M}$. We found that when $\mathrm{M}=\mathrm{Li}, \quad\left[\mathrm{Li}_{3}(\mathrm{THF})_{4}\right]\left[(\text { BINOLate })_{3} \mathrm{Ce}(\mathrm{THF})\right]$ (1$\mathbf{C e}($ homo)), wherein all the BINOLate ligands have the same configuration, the complex could readily reorganize to stabilize similar coordination numbers and geometries upon oxidation (Fig. 1). This characteristic facilitated general, predictable, and controlled oxidation chemistry. The net result of this ligand reorganization was striking, a seemingly small perturbation such as shifting the equilibrium constant for coordination of a Lewis basic ligand (THF, TPPO) at the RE cation led to over a 130-fold difference in chemical oxidation rates and resulted in completely different product outcomes.

While the impact of ligand reorganization on cerium redox chemistry has been demonstrated experimentally, ${ }^{7,8}$ the impact of other associated dynamic processes, such as ligand exchange/redistribution, have yet to be determined. These studies are necessary to understand the prevalence of redistribution products observed for oxidation reactions of $\mathrm{Ce}^{\mathrm{III}} .^{5 a, c, 8 b, 9}$ As such, we set out to explore the impact of ligand exchange/ redistribution, and delineate their contributions from that of ligand reorganization on the observed reactivity and properties involving oxidation of $\mathrm{Ce}^{\mathrm{III}}$. Herein we report the synthesis and characterization of the novel Ce/Li REMB heterochiral diastereomer, 1-Ce(het), which displays reactivity that is controlled by both ligand reorganization and redistribution processes. Ligand reorganization largely contributed to the kinetics of the chemical oxidation, whereas ligand redistribution and exchange dictated the ultimate isolated products. Characterization of the ligand exchange processes of 1-RE(het) ( $\mathrm{RE}=\mathrm{Ce}$ and $\mathrm{Yb}$ ) facilitated the quantification of $\mathrm{Li}^{+}$and BINOLate exchange of these frameworks. Our study sheds light on relevant dynamic processes and provides insight into the available pathways possible in $\mathrm{Ce}^{\mathrm{III}}$ oxidation chemistry.

\section{Results and discussion}

As we set out to study and parse the effects of ligand reorganization, redistribution, and exchange on the oxidation chemistry of $\mathrm{Ce}^{\mathrm{III}}$, we needed a framework that would enable the systematic control of these processes. We postulated that mixtures of homochiral and heterochiral diastereomers of the Ce/Li REMB framework, 1-Ce(homo) and 1-Ce(het), respectively, could meet our needs. We recently demonstrated the effects of ligand reorganization and neutral ligand exchange in the $\mathrm{Ce}^{\mathrm{III}} / \mathrm{Li}^{+}$ system, 1-Ce(homo). ${ }^{7}$ Aspinall, ${ }^{10}$ Salvadori, ${ }^{11}$ and Shibasaki, ${ }^{12}$ have independently demonstrated that: (1) (SSR)- or $(R R S)$ $\left[\mathrm{Li}_{3}(\mathrm{THF})_{6}\right]\left[(\mathrm{BINOLate})_{3} \mathrm{RE}\right], \mathbf{1 - R E}($ het $)\left(\mathrm{RE}^{\mathrm{III}}=\mathrm{Y}\right.$ or $\left.\mathrm{Yb}\right)$, were sixcoordinate RE complexes in the solid state, (2) $\mathrm{Yb}^{\mathrm{III}}$ cations in these frameworks were not accessible to additional coordination by Lewis bases, and (3) mixtures of enantiopure $\left[\mathrm{Li}_{3}(\mathrm{THF})_{6}\right]$ [(BINOLate) $\left.)_{3} \mathrm{Y}\right],(\boldsymbol{S S S})-\mathbf{- 1} \mathbf{Y}(\mathbf{h o m o})$ and (RRR)-1-Y(homo), underwent ligand redistribution to form the thermodynamically preferred heterochiral diastereomer, 1-Y(het), respectively. While seminal contributions, these studies have not investigated the rates of inter- or intramolecular BINOLate and cation exchange, nor the synthesis of $\mathrm{RE}^{\mathrm{III}}$ larger than $\mathrm{Y}^{\mathrm{III}}$. In this context, we sought to synthesize the novel heterochiral diastereomer, 1-Ce(het), characterize its dynamic exchange processes and determine the effects of those processes on the electrochemical and chemical oxidation properties of $\mathrm{Ce}^{\mathrm{III}}$.

\section{Synthesis and characterization of 1-Ce(het)}

Initially, we examined salt-metathesis synthetic routes with $\mathrm{Ce}(\mathrm{OTf})_{3}$, (rac)-BINOL, and $\mathrm{LiN}\left(\mathrm{SiMe}_{3}\right)_{2}$ or $\mathrm{Li}\left(\mathrm{O}^{t} \mathrm{Bu}\right)$, which resulted in formation of 1-Ce(het). Unfortunately, isolation of analytically pure heterobimetallic product was complicated due to the similar solubilities of 1-Ce(het) and the salt by-products (LiOTf). Similar to 1-Ce(homo), the synthesis of $\left[\mathrm{Li}_{3}(\mathrm{THF})_{6}\right]$ [(BINOLate $\left.)_{3} \mathrm{Ce}\right]$, 1-Ce(het), was accomplished through protonolysis by adding 3 equiv. each of racemic BINOL and $\mathrm{Li}\left(\mathrm{N}\left(\mathrm{SiMe}_{3}\right)_{2}\right.$ to a stirring THF solution of $\mathrm{Ce}\left[\mathrm{N}\left(\mathrm{SiMe}_{3}\right)_{2}\right]_{3}$. Layering concentrated THF solutions of 1-Ce(het) with hexanes $(1: 4 \mathrm{v} / \mathrm{v})$ at $-35{ }^{\circ} \mathrm{C}$ produced bright yellow-orange crystals in $74 \%$ yield (Scheme 1 ).

\section{Solid-state characterization of 1-Ce(het)}

$\mathrm{X}$-ray diffraction studies confirmed the formation of the expected racemic heterochiral diastereomer, 1-Ce(het) $(R R S / S S R$, Fig. 2), where the coordination environment of the $\mathrm{Ce}^{\mathrm{III}}$ cation was isostructural to the known complexes 1-Y(het) and 1$\mathbf{Y b}$ (het). ${ }^{10}$ Orientation of the $R R S / S S R$ BINOLate fragments lead to a different coordination environment for 1-Ce(het) compared to $1-\mathbf{C e}(\mathbf{h o m o})$. Whereas the $\mathrm{Ce}^{\mathrm{III}}$ cation in 1-Ce(homo) readily accommodated a seventh ligand (THF or TPPO), the heterochiral arrangement of the BINOLate fragments sterically block the $\mathrm{Ce}^{\mathrm{III}}$ cation in 1-Ce(het) toward interaction with donor solvents such as THF. Average $\mathrm{Ce}^{\mathrm{III}}-\mathrm{O}_{\mathrm{BINOLate}}$ bond distances for 1-Ce(het) were shorter by $0.0380(1) \AA$ compared to 1-Ce(homo), and reflect the difference in ionic radii between six- and sevencoordinate Ce $\mathrm{III}^{\mathrm{III}}$ cations. ${ }^{13}$ The decreased coordination number at the $\mathrm{Ce}^{\mathrm{III}}$ cation in 1-Ce(het) versus 1-Ce(homo) was accompanied by increased solvation at the $\mathrm{Li}^{+}$cations, providing further stabilization for 1-Ce(het). Similar to solid state structures of 1-Y(het) and $\mathbf{1 - Y b}(\mathbf{h e t}),{ }^{10}$ a weak $\mathrm{C}-\mathrm{H}$ to $\pi$ hydrogen

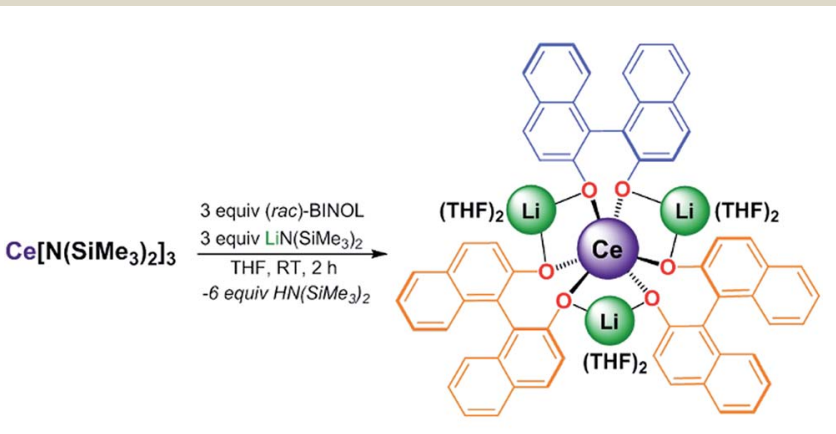

(rac)-1-Ce(het)

Scheme 1 Synthesis of (rac)-1-Ce(het). The BINOLate ligands have been colored blue and orange to clearly indicate the heterochiral configuration of the BINOLate ligand fragments as found in the X-ray crystal structure. 


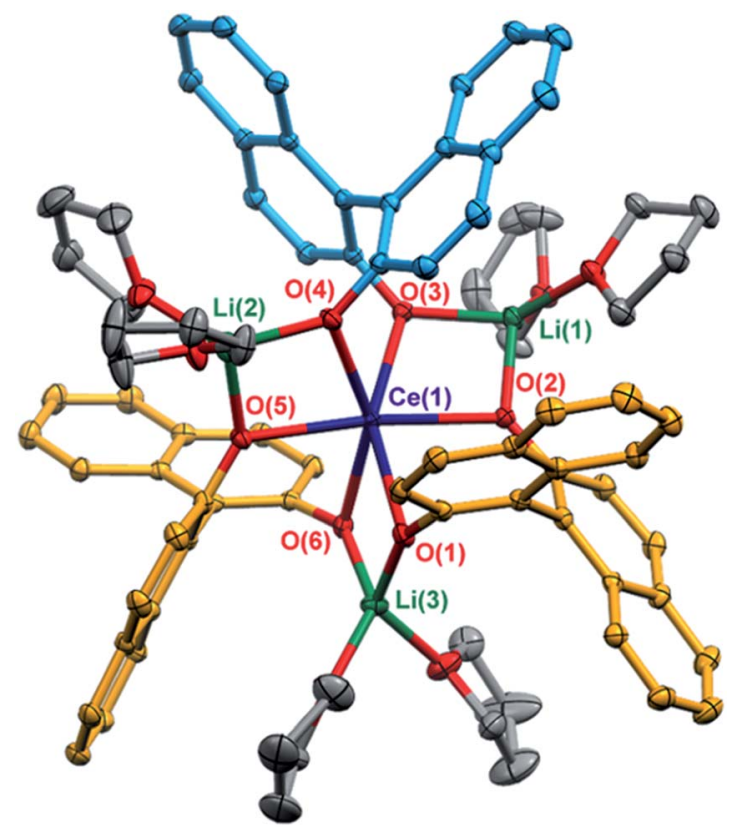

Fig. 2 Thermal ellipsoid plot of 1-Ce(het) shown at 30\% probability. The BINOLate ligands have been colored blue and orange to indicate the $S S / R R$ and $R / S$ fragments respectively. Selected bond distances $(\AA)$ : $\mathrm{Ce}(1)-\mathrm{O}(1)$ 2.3908(16), $\mathrm{Ce}(1)-\mathrm{O}(2)$ 2.3924(16), $\mathrm{Ce}(1)-\mathrm{O}(3) 2.3900(17)$, $\mathrm{Ce}(1)-\mathrm{O}(4)$ 2.3947(16), $\mathrm{Ce}(1)-\mathrm{O}(5)$ 2.3743(16), $\mathrm{Ce}(1)-\mathrm{O}(6)$ 2.3909(17), $\mathrm{Li}(1)-\mathrm{O}(2) 1.888(5), \mathrm{Li}(1)-\mathrm{O}(3) 1.946(4), \mathrm{Li}(2)-\mathrm{O}(4) 1.927(5), \mathrm{Li}(2)-\mathrm{O}(6)$ 1.899(5), Li(3)-O(1) 1.946(4), Li(3)-O(5) 1.955(4).

bond was observed between a BINOLate $\mathrm{C}-\mathrm{H}$ and the neighboring BINOLate naphthyl $\pi$ system (Fig. S21†).

\section{Solution NMR characterization of 1-Ce(het)}

While 1-Ce(het) was identified as the only diastereomer in the solid state, ${ }^{1} \mathrm{H}-,{ }^{7} \mathrm{Li}-$, and ${ }^{13} \mathrm{C}\left\{{ }^{1} \mathrm{H}\right\}$-NMR spectroscopy revealed a varied energy landscape in solution (Fig. 3). Dissolving crystals of 1-Ce(het) in THF- $d_{8}$ resulted in two major solution species, 1$\mathbf{C e}($ het) and 1-Ce(homo). These diastereomers were readily identified using $1 \mathrm{D}^{1} \mathrm{H}-,{ }^{7} \mathrm{Li}-$, and ${ }^{13} \mathrm{C}\left\{{ }^{1} \mathrm{H}\right\}$-NMR (Fig. 3) and 2DNMR correlation spectroscopy (COSY and HSQC; Fig. S5 and $\mathrm{S} 6 \dagger$ ) techniques. As determined by integration of ${ }^{1} \mathrm{H}$ and ${ }^{7} \mathrm{Li}$ NMR spectra, 1-Ce(het) and 1-Ce(homo) were present in a $\sim 6: 1$ ratio $(K=0.17)$, which corresponded to an energy difference $\Delta G$ $(300 \mathrm{~K})$ of $0.63 \mathrm{kcal} \mathrm{mol}^{-1}$ between the two diastereomeric forms. In comparison, $\Delta G(300 \mathrm{~K})$ must be greater than $1.79 \mathrm{kcal}$ $\mathrm{mol}^{-1}(K \approx 0.05)$ for the smaller REs, $\mathrm{Y}^{\mathrm{III}}$ and $\mathrm{Yb}^{\mathrm{III}}$, as the homochiral diastereomers were reportedly not observed using solution NMR spectroscopy. ${ }^{\mathbf{1 0 , 1 2}}$

The energy differences for the two diastereomers, 1$\mathbf{R E}($ homo) and 1-RE(het), are a consequence of the ionic radii of the $\mathrm{RE}^{\mathrm{III}}$ cation. $\mathrm{Ce} \mathrm{III}^{\mathrm{II}}$, a large $\mathrm{RE}^{\mathrm{III}}$ cation, can more readily accommodate a seven-coordinate geometry than a small RE like $\mathrm{Yb}^{\mathrm{III}}$ due to increased steric accessibility. ${ }^{7,14}$ In turn, this enthalpic gain from coordination of a seventh ligand stabilizes formation of the homochiral diastereomer, and is more favorable for the early $\mathrm{RE}^{\mathrm{III}}$. This observation was further supported by ${ }^{1} \mathrm{H}$ and ${ }^{7} \mathrm{Li}$-NMR spectroscopy performed in a more strongly

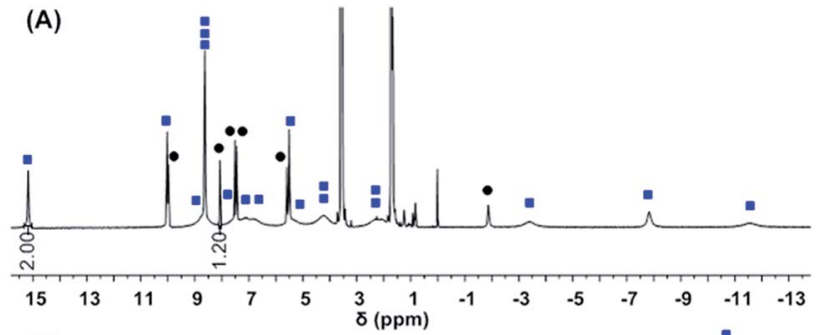

(B)

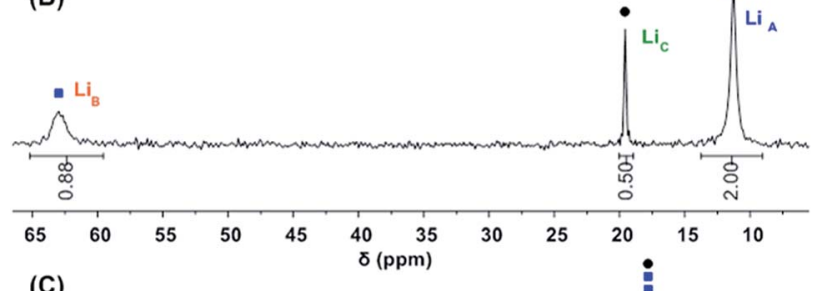

(C)

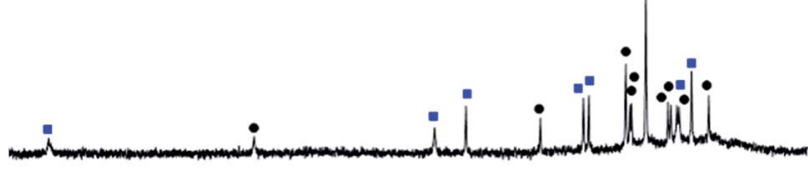

$\begin{array}{llllllllllllll}195 & 190 & 185 & 180 & 175 & 170 & 165 & 160 \\ \delta(\mathrm{ppm}) & 155 & 150 & 145 & 140 & 135 & 130 & 125 & 120 & 115\end{array}$

Fig. 3 (A) ${ }^{1} \mathrm{H}$ - (top), (B) ${ }^{7} \mathrm{Li}-\mathrm{NMR}$ (middle), and (C) ${ }^{13} \mathrm{C}\left\{{ }^{1} \mathrm{H}\right\}-\mathrm{NMR}$



coordinating solvent, pyridine- $d_{5}\left(\right.$ pyr- $\left.d_{5}\right)$. In pyr- $d_{5}$ only the homochiral diastereomer $\left[\mathrm{Li}_{3}(\mathrm{sol})_{n}\right]\left[(\mathrm{BINOLate})_{3} \mathrm{Ce}(\mathrm{sol})\right]$ (sol = pyr; $n=5$ ), 1-Ce(homo), was observed by NMR (Fig. S3†). These results indicated that the thermodynamic preference of the diastereomeric forms in solution cannot only be controlled by the size of $\mathrm{RE}^{\mathrm{III}}$ cation, but also through choice of solvent.

Solution concentrations of the heterochiral and homochiral diastereomers of 1-RE $(\mathrm{RE}=\mathrm{Ce}$ and $\mathrm{Yb})$ were determined by ${ }^{1} \mathrm{H}$ and ${ }^{7} \mathrm{Li}-\mathrm{NMR}$ spectroscopy over a range of optical purities (0$100 \%$ ee). Non-linear relationships between the concentration of 1-RE(homo) and optical purity of BINOL were observed for both $\mathrm{Ce}^{\mathrm{III}}$ (Fig. 4) and $\mathrm{Yb}^{\mathrm{III}}$ cations (Fig. S16†). Ligand redistribution/exchange reactions between 1-RE(het) and 1-RE(homo)

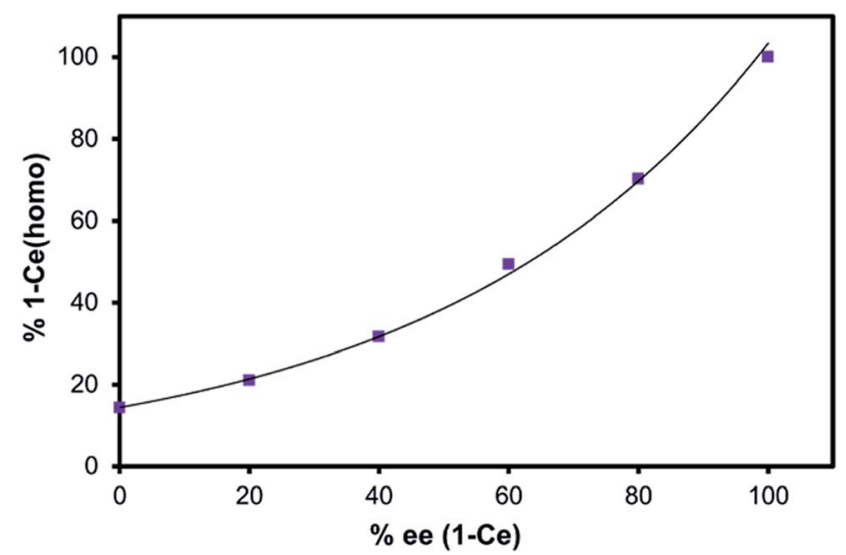

Fig. 4 Enantiomeric excess of BINOLate versus percent 1-Ce(homo) in solution ("Li-NMR integration). Line provided as a guide for the eye. 
$(\mathrm{RE}=\mathrm{Ce}, \mathrm{Yb})$ were completed before the time needed to prepare and record the NMR spectra $(<2 \mathrm{~min})$. Variable-temperature NMR (VT-NMR) studies indicated that the equilibrium constant for 1-Ce(het)/1-Ce(homo) was effectively temperature independent over the range of 215 to $315 \mathrm{~K}$ (Fig. S7†).

\section{Solution NMR characterization - ligand exchange and redistribution of 1-RE(het)/1-RE(homo) $(\mathrm{RE}=\mathrm{Yb}, \mathrm{Ce})$}

After establishing that an equilibrium between 1-Ce(het) and 1Ce(homo) existed in solution, we set out to establish rates of ligand and cation exchange for the system. While the groups of Aspinall, ${ }^{10}$ Shibasaki, ${ }^{12}$ and Salvadori ${ }^{\mathbf{1 1}}$ have independently investigated solution behavior of heterochiral $\left[\mathrm{Li}_{3}(\mathrm{THF})_{6}\right]$ $\left[(\text { BINOLate })_{3}\right.$ RE] complexes, 1-RE(het), limited investigations have been made towards characterizing the exchange processes of these complexes. Only Shibasaki and coworkers have demonstrated that the thermodynamically preferred heterochiral diastereomer, 1-Y(het), can be formed through ligand exchange between mixtures of enantiopure (SSS)-1-Y(homo) and (RRR)-1-Y(homo). Quantification of ligand exchange rates, however, have yet to be established.

Two-dimensional exchange spectroscopy (2D-EXSY) has emerged as a useful technique to determine rates of chemical exchange that are slow on the NMR timescale. ${ }^{15}$ The technique has been successfully applied to a number of diverse chemical systems and nuclei, including ${ }^{1} \mathrm{H}$ and ${ }^{7} \mathrm{Li}$ nuclei and paramagnetic metal cations. ${ }^{15 b, 16}$ Recently, we have employed this technique to determine BINOLate and $\mathrm{Li}^{+}$exchange for 1$\mathbf{R E}\left(\right.$ homo) under catalytically relevant conditions. ${ }^{17}$

BINOLate and $\mathrm{Li}^{+}$exchange: $1-\mathrm{Yb}(\mathrm{het})$. We began our investigation by studying ligand and $\mathrm{Li}^{+}$exchange of $\mathbf{1 - Y b}(\mathbf{h e t})$ to facilitate a more straightforward assignment and interpretation of any observed exchange processes between 1-RE(homo) and 1$\mathbf{R E}($ het $)\left(\mathrm{RE}^{\mathrm{III}}=\mathrm{Ce}\right.$ and $\left.\mathrm{Yb}\right)$. Previous reports have indicated that (rac)-1-Yb(het) exists as a racemic mixture of a single diastereomer in solution, and will help distinguish intra- and intermolecular exchange processes in 1-RE(het) and 1-RE(het)/1$\mathbf{R E}($ homo) systems. Additionally, we expected that the paramagnetism of the $\mathrm{Yb}^{\mathrm{III}}$ cation would provide suitable resolution of ${ }^{1} \mathrm{H}$ - and ${ }^{7} \mathrm{Li}$-NMR resonances of exchanging species to enable quantitative analysis using 2D-EXSY NMR experiments. ${ }^{15 b}$

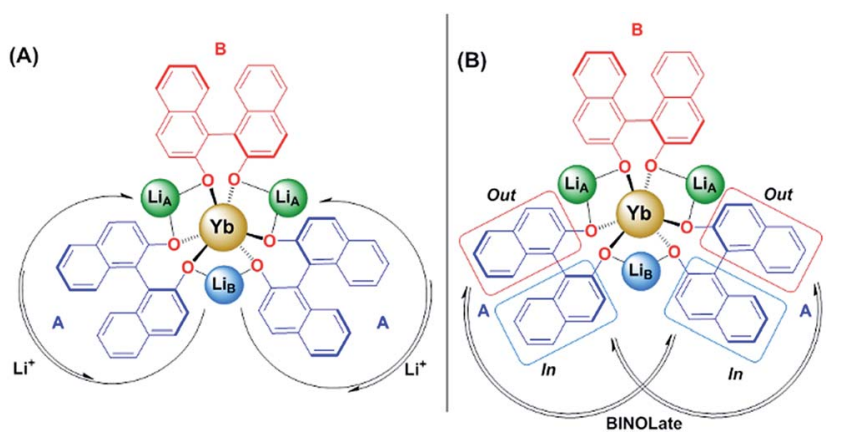

Scheme 2 Proposed (A) $\mathrm{Li}^{+}$and (B) BINOLate exchange processes for $1-\mathrm{Yb}$ (het) $\left(19.3 \mathrm{mM} ; 1-\mathrm{Yb}=0 \%\right.$ ee) as determined from $2 \mathrm{D}^{1} \mathrm{H}$ and ${ }^{7} \mathrm{Li}$ $\left\{{ }^{1} H\right\}-N M R$ EXSY experiments. Bound solvents not shown.

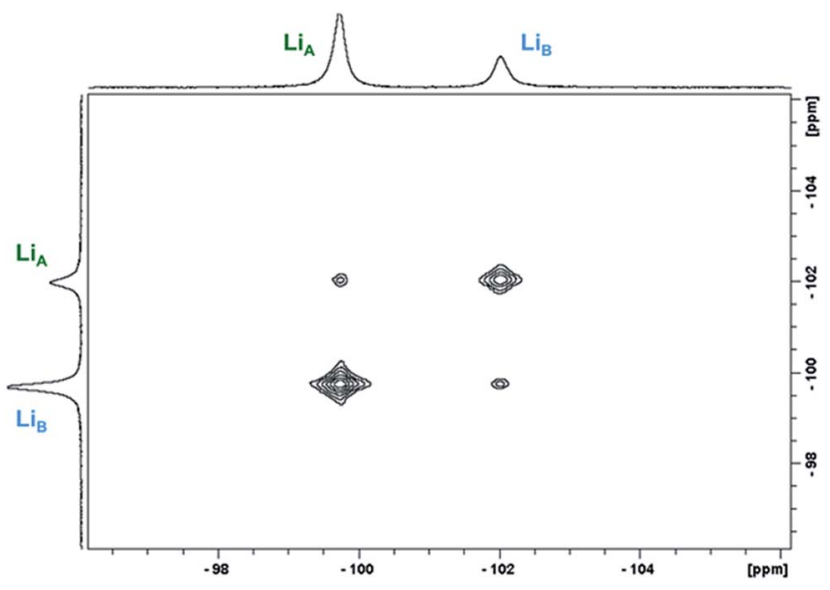

Fig. 5 Representative 2D ${ }^{7}$ Li-NMR EXSY experiment of 1-Yb(het) (19.3 $\mathrm{mM} ; t_{\text {mix }}=5 \mathrm{~ms}, 300 \mathrm{~K} ; 1-\mathrm{Yb}=0 \%$ ee) taken in THF- $d_{8}$.

$2 \mathrm{D}{ }^{1} \mathrm{H}$ - and ${ }^{7} \mathrm{Li}-\mathrm{NMR}$ EXSY experiments were performed on a $19.3 \mathrm{mM}$ solution of $\mathbf{1 - Y b}(\mathbf{h e t})$ and were collected at $300 \mathrm{~K}$ with a mixing time $\left(t_{\text {mix }}\right)$ of $5 \mathrm{~ms}$. Proposed $\mathrm{Li}^{+}$(Scheme $2 \mathrm{~A}$ ) and BINOLate (Scheme 2B) exchange processes are depicted in Scheme 2. The two inequivalent $\mathrm{Li}^{+}$cations, $\mathrm{Li}_{\mathrm{A}}$ and $\mathrm{Li}_{\mathrm{B}}$, readily underwent exchange at $300 \mathrm{~K}$, where the pseudo-first order rate constants for exchange of $\mathrm{Li}_{\mathrm{A}} \rightarrow \mathrm{Li}_{\mathrm{B}}$ and $\mathrm{Li}_{\mathrm{B}} \rightarrow \mathrm{Li}_{\mathrm{A}}$ were 34.0 and $80.1 \mathrm{~s}^{-1}$ respectively (Fig. 5 and Table 1 ). Comparable rates of exchange were observed for $S S / R R$ and $R / S$ BINOLate fragments $\left(k_{\mathrm{obs}}=78.3\right.$ and $79.5 \mathrm{~s}^{-1}$, Table 1 and Fig. S12 $\left.\dagger\right)$, which were $\sim 100$-fold faster than we previously observed for rates of intermolecular BINOLate exchange between 1-Pr(homo)/1Eu(homo). ${ }^{17}$

Both BINOLate and $\mathrm{Li}^{+}$exchange processes were assigned as intramolecular due to: (1) observed exchange rates being independent of the concentration of $\mathbf{1 - Y b}(\mathbf{h e t})$, and (2) activation parameters that were significantly different compared to the intermolecular processes observed between 1-Pr(homo) and 1$\mathbf{E u}(\mathbf{h o m o})$. Values of $k_{\text {obs }}$ were insensitive to the concentration of $\mathbf{1 - Y b}(\mathbf{h e t})$, where a 2-fold dilution resulted in minimal changes of rate (Table 1). Further support for the assignment of an intramolecular BINOLate exchange observed in 1-Yb(het) is

Table $12 \mathrm{D}{ }^{1} \mathrm{H}$ and ${ }^{7} \mathrm{Li}-\mathrm{NMR}$ EXSY rate data and activation parameters for $1-\mathrm{Yb}$ (het) $\left(19.3 \mathrm{mM} ; t_{\text {mix }}=5 \mathrm{~ms} ; \mathrm{BINOL}=0 \%\right.$ ee)

\begin{tabular}{lllll}
\hline $\begin{array}{l}\text { Exchange } \\
\text { process }\end{array}$ & $\begin{array}{l}k_{\mathrm{obs}}^{a, b} \\
\left(\mathrm{~s}^{-1}\right)\end{array}$ & $\begin{array}{l}\Delta H^{\ddagger c} \\
\left(\mathrm{kcal} \mathrm{mol}^{-1}\right)\end{array}$ & $\begin{array}{l}\Delta S^{\ddagger c} \\
(\mathrm{eu})\end{array}$ & $\begin{array}{l}\Delta G^{\ddagger c} \\
\left(\mathrm{kcal} \mathrm{mol}^{-1}\right)\end{array}$ \\
\hline
\end{tabular}

$\mathbf{L i}^{+}$

$\begin{array}{lllll}\mathrm{A} \rightarrow \mathrm{B} & 34.0(31.4)^{d} & 15.1 & -12.2 & 16\end{array}$

$\mathrm{B} \rightarrow \mathrm{A} \quad 80.1(79.8)^{d} \quad 16.9 \quad 19.0 \quad 15.5$

BINOLate

$\mathrm{A}_{\text {in }} \rightarrow \mathrm{A}_{\text {out }}{ }^{e} \quad 78.3(82.5)^{d} \quad 14.2 \quad-17.7 \quad 15.4$

$\mathrm{A}_{\text {out }} \rightarrow \mathrm{A}_{\mathrm{in}}{ }^{e} \quad 79.5(79.6)^{d} \quad 14.9 \quad-8.3 \quad 15.5$

${ }^{a}$ At $310 \mathrm{~K} .{ }^{b}$ Determined using EXSYCalc. ${ }^{18}{ }^{c}$ At $298 \mathrm{~K} .{ }^{d}$ 2-fold dilution of 1-Yb(het). ${ }^{e}$ Exchange between $\mathrm{A}_{\text {in }}$ and $\mathrm{A}_{\text {out }}$ (Scheme 2B) correspond to peak assignments $\mathrm{A}(3)$ and $\mathrm{A}(10)$ (see ESI, Fig. S1 and S10-S12). 


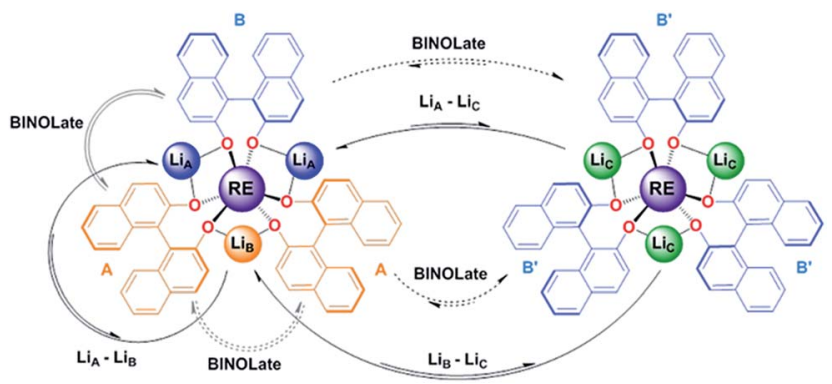

Scheme 3 Representative intra- and inter-molecular exchange processes for ( $\mathrm{rac}$ )-1-RE(het) and 1-RE(homo) $(\mathrm{RE}=\mathrm{Ce}$ and $\mathrm{Yb})$ from $2 D^{1} \mathrm{H}$ and ${ }^{7} \mathrm{Li}-\mathrm{NMR}$ EXSY experiments. Dashed lines indicate equilibria that were not directly observable by EXSY experiments, but have been observed through simple 1D mixing experiments (vide supra) or 2D EXSY experiments with 1-RE(homo). ${ }^{17}$

the $\sim 100$-fold increase in rate compared to the previously reported intermolecular BINOLate exchange between 1-Pr(homo)/ 1-Eu(homo). While the magnitude of $\Delta S^{\ddagger}$ was non-zero for BINOLate and $\mathrm{Li}^{+}$exchange processes, $\Delta S^{\dagger}$ was significantly smaller than that determined for intermolecular exchange $(\sim 50$ and 105 eu respectively) and support assignment as an intramolecular exchange process.

BINOLate and $\mathrm{Li}^{+}$exchange: 1-RE(het)/1-RE(homo) $(\mathrm{RE}=\mathrm{Ce}$, Yb). With intramolecular exchange processes identified for 1$\mathbf{Y b}($ het), we next examined the relevant intra- and intermolecular exchange processes for a mixture of 1-Yb(het)/1-Yb(homo) (Scheme 3). 2D EXSY experiments were performed on solutions of enantioenriched 1-Yb (77\% ee; 1 : 1.4 ratio of 1-Yb(het) : 1$\mathbf{Y b}$ (homo)) over the temperature range of 300-330 $\mathrm{K}$ (Table 2 and Fig. 6). In addition to the previously established intramolecular exchange processes, ${ }^{7} \mathrm{Li}-\mathrm{NMR}$ EXSY experiments performed at $310 \mathrm{~K}\left(t_{\text {mix }}=10 \mathrm{~ms}\right)$ revealed intermolecular $\mathrm{Li}^{+}$ exchange processes (Table 2 and Fig. 6). Exchange occurred between the three possible sites, $\mathrm{Li}_{\mathrm{A}}, \mathrm{Li}_{\mathrm{B}}$, and $\mathrm{Li}_{\mathrm{C}}$, where the rate

Table 2 2D ${ }^{1} \mathrm{H}$ - and ${ }^{7} \mathrm{Li}-\mathrm{NMR}$ EXSY rate data and activation parameters for $1-\mathrm{Yb}$ (het)/1-Yb(homo) $\left(9.64 \mathrm{mM} / 32.7 \mathrm{mM} ; t_{\text {mix }}\left(\mathrm{Li}^{+}\right)=10 \mathrm{~ms}\right.$; $t_{\text {mix }}(B I N O L a t e)=5 \mathrm{~ms} ; 1-Y b=77 \%$ ee $)$

\begin{tabular}{lllll}
\hline $\begin{array}{l}\text { Exchange } \\
\text { process }\end{array}$ & $\begin{array}{l}k^{a, b} \\
\left(\mathrm{~s}^{-1}\right)\end{array}$ & $\begin{array}{l}\Delta H^{\ddagger c} \\
\left(\mathrm{kcal} \mathrm{mol}^{-1}\right)\end{array}$ & $\begin{array}{l}\Delta S^{\ddagger c} \\
(\mathrm{eu})\end{array}$ & $\begin{array}{l}\Delta G^{\ddagger c} \\
\left.(\mathrm{kcal} \mathrm{mol})^{-1}\right)\end{array}$ \\
\hline
\end{tabular}

$\mathbf{L i}^{+}$

$\begin{array}{lllll}\mathrm{A} \rightarrow \mathrm{B} & 44.3(34.0)^{d} & 12.0 & -52.3 & 15.7 \\ \mathrm{~B} \rightarrow \mathrm{A} & 92.8(80.1)^{d} & 13.4 & -25.3 & 15.2 \\ \mathrm{~A} \rightarrow \mathrm{C} & 3.37 & 12.5 & -66.8 & 17.3 \\ \mathrm{C} \rightarrow \mathrm{A} & 2.78 & 11.8 & -76.8 & 17.3 \\ \mathrm{~B} \rightarrow \mathrm{C} & 7.12 & 8.06 & -120 & 16.6 \\ \mathrm{C} \rightarrow \mathrm{B} & 3.16 & 4.55 & -175 & 17.0\end{array}$

BINOLate

$\begin{array}{lllrr}\mathrm{A}_{\text {in }} \rightarrow \mathrm{A}_{\text {out }}{ }^{e} & 77.4(78.3)^{d} & 14.2 & -17.7 & 15.4 \\ \mathrm{~A}_{\text {out }} \rightarrow \mathrm{A}_{\text {in }}{ }^{2} & 80.3(79.5)^{d} & 14.9(78.3)^{d} & -8.3 & 15.5\end{array}$

${ }^{a}$ At $310 \mathrm{~K} .{ }^{b}$ Determined using EXSYCalc. ${ }^{18}{ }^{c}$ At $298 \mathrm{~K} .{ }^{d}$ Values for 1Yb(het) $(19.3 \mathrm{mM}) .{ }^{e}$ Exchange between $\mathrm{A}_{\mathrm{in}}$ and $\mathrm{A}_{\text {out }}$ (Scheme $2 \mathrm{~B}$ ) correspond to peak assignments $\mathrm{A}(3)$ and $\mathrm{A}(10)$ (see ESI, Fig. S1 and S10-S12).



Fig. 6 Representative 2D ${ }^{7} \mathrm{Li}-\mathrm{NMR}$ EXSY experiment of 1-Yb(het)/1$\mathrm{Yb}$ (homo) (9.64 mM/32.7 mM; $t_{\text {mix }}=15 \mathrm{~ms}, 300 \mathrm{~K} ; 1-\mathrm{Yb}=77 \%$ ee) taken in $\mathrm{THF}-d_{8}$.

of intermolecular exchange was an order of magnitude slower than intramolecular exchange.

Intermolecular BINOLate exchange processes were not observed by ${ }^{1} \mathrm{H}$ 2D EXSY NMR experiments, despite previous observation of intermolecular exchange between different 1$\mathbf{R E}\left(\right.$ homo) $\left(\mathrm{RE}=\mathrm{Pr}\right.$ and Eu). ${ }^{17}$ Qualitatively, we have demonstrated that ligand redistribution is a facile process at RT (optical purity experiments, vide supra). To explain the absence of observable exchange using ${ }^{1} \mathrm{H}$ 2D EXSY NMR experiments, we propose that BINOLate exchange between the diastereomers is either slow on the EXSY NMR time scale or at least slower than the relaxation rates rendered by the paramagnetic $\mathrm{Yb}^{\mathrm{III}}$ cation.

Quantification of $\mathrm{Li}^{+}$and BINOLate exchange rates between 1-Ce(het) and 1-Ce(homo) proved more challenging. The peak shape of the BINOLate $\mathrm{C}-\mathrm{H}$ of $1-\mathrm{Ce}($ het) are significantly broadened in the presence of 1-Ce(homo) (full width at half maximum, $\nu_{\text {FWHM }} \sim 25-180 \mathrm{~Hz}$ ). The broadened peaks, coupled with rapid relaxation rates and insufficient spectral resolution precluded clear observation of intramolecular and intermolecular BINOLate exchange through EXSY techniques. Similar to 1Yb(het)/1-Yb(homo), intra- and intermolecular $\mathrm{Li}^{+}$exchange occurred between all three possible sites $-\mathrm{Li}_{\mathrm{A}}, \mathrm{Li}_{\mathrm{B}}$, and $\mathrm{Li}_{\mathrm{C}}$ (Scheme 3 and Fig. S15†). Intramolecular $\mathrm{Li}^{+}$exchange occurred at much faster rates, and prevented a full quantitative treatment under experimental conditions investigated. Notably, intramolecular $\mathrm{Li}^{+}$exchange for 1-RE(het) in the presence of 1$\mathbf{R E}$ (homo) occurred $\sim 5$ times faster for $\mathrm{Ce}^{\mathrm{III}}$ compared to the smaller $\mathrm{Yb}^{\mathrm{III}}$ cation (115 and $23 \mathrm{~s}^{-1}$ at $300 \mathrm{~K}$ respectively), and indicates increased $\mathrm{Li}^{+}$lability with a larger $\mathrm{RE}^{\mathrm{III}}$ cation.

To summarize, by using $2 \mathrm{D}{ }^{1} \mathrm{H}$ - and ${ }^{7} \mathrm{Li}-\mathrm{NMR}$ EXSY we have established that intramolecular and intermolecular exchange processes occurred readily for 1-RE(het) and mixtures of 1$\mathbf{R E}($ het $) / \mathbf{1}-\mathbf{R E}\left(\right.$ homo) $(\mathrm{RE}=\mathrm{Ce}$ and $\mathrm{Yb})$. For $\mathrm{Yb}^{\mathrm{III}}$, activation parameters provided experimental support for the assignment of intramolecular and intermolecular exchange processes. Quantitation of intermolecular BINOLate exchange was not possible using EXSY techniques, however, rapid rates of ligand 
redistribution at $\mathrm{RT}$ were established qualitatively through NMR spectroscopy. Rapid equilibration was confirmed by mixing enantiomers of 1-RE(homo) at varying optical purities, where the enantiomers rapidly equilibrated to 1-RE(het) and 1RE(homo).

\section{Electrochemical and chemical oxidation behavior of 1-Ce(het)}

After synthesizing 1-Ce(het) and establishing that ligand exchange/redistribution occurred readily between 1-Ce(het) and 1-Ce(homo), the electrochemical and chemical oxidation behavior of 1-Ce(het) and 1-Ce(homo) was investigated to determine the role of these processes on the oxidation chemistry of $\mathrm{Ce}^{\mathrm{III}}$.

Electrochemistry of 1-Ce(het)/1-Ce(homo). Previously, we demonstrated that the homochiral CeMB (M $=\mathrm{Li}, \mathrm{Na}, \mathrm{K}, \mathrm{Cs})$ frameworks displayed chemical oxidation reactivity that did not correspond with rates of electrochemical oxidation. ${ }^{7}$ In the current study, cyclic voltammetry was performed for 1-Ce(het) (1-Ce $=0 \%$ ee) in THF solutions using $0.1 \mathrm{M}\left[\mathrm{NPr}_{4}\right]\left[\mathrm{B}\left(\mathrm{Ar}^{\mathrm{F}}\right)_{4}\right]\left(\mathrm{Ar}^{\mathrm{F}}\right.$ $\left.=3,5-\left(\mathrm{CF}_{3}\right)_{2}-\mathrm{C}_{6} \mathrm{H}_{3}\right)$ as supporting electrolyte (Fig. 7). Cyclic voltammograms of 1-Ce(het) revealed diffusion controlled responses with two kinetically irreversible metal oxidation events, $E_{\mathrm{pa}}(1)$ and $E_{\mathrm{pa}}(2)$, followed by two return reduction waves, $E_{\mathrm{pc}}(1)$ and $E_{\mathrm{pc}}(2)$. Consistent with our spectroscopic studies, we have assigned $E_{\mathrm{p}}(1)$ and $E_{\mathrm{p}}(2)$ to two unique electrochemically active species: 1-Ce(het) and 1-Ce(homo) respectively (for more details regarding wave assignments see ESI, Fig. S17†).

For a racemic solution of 1-Ce(het)/1-Ce(homo), oxidation of 1-Ce(het) $\left(E_{\mathrm{pa}}(1)=-0.860 \mathrm{~V}\right.$ vs. Fc) occurred at $275 \mathrm{mV}$ more reducing than that of $1-\mathrm{Ce}($ homo $)\left(E_{\mathrm{p}}(2)=-0.585 \mathrm{~V}\right)$. This is consistent with a more electron rich $\mathrm{Ce}^{\mathrm{III}}$ cation in 1-Ce(het), which could be expected from the shorter Ce-O $\mathrm{O}_{\text {BINOLate }}$ distances observed in the solid state..$^{5,7,19}$ In addition to a higher driving force, the heterogeneous electron transfer occurs at a slightly faster rate for 1-Ce(het), which can be qualitatively determined by the separation of the oxidation and reduction events, $\Delta E_{\mathrm{p}}$, for 1-Ce(het) and 1-Ce(homo) (450 mV versus 490

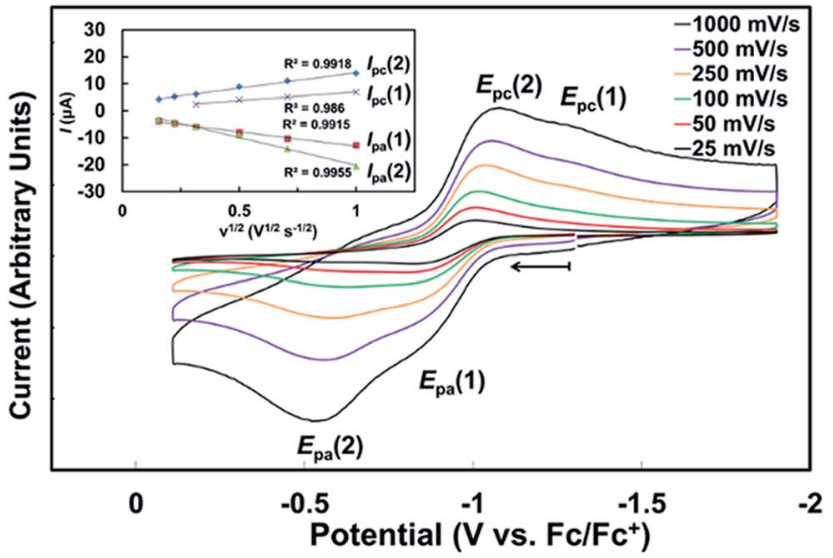

Fig. 7 Cyclic voltammogram of 1-Ce(het) ([Ce] $=\sim 1 \mathrm{mM}$; $\mathrm{THF}_{\text {, }}\left[\mathrm{NPr}_{4}\right]$ $\left.\left[\mathrm{B}\left(\mathrm{Ar}^{\mathrm{F}}\right)_{4}\right]=100 \mathrm{mM}, \nu=500 \mathrm{mV} \mathrm{s}^{-1}\right)$.

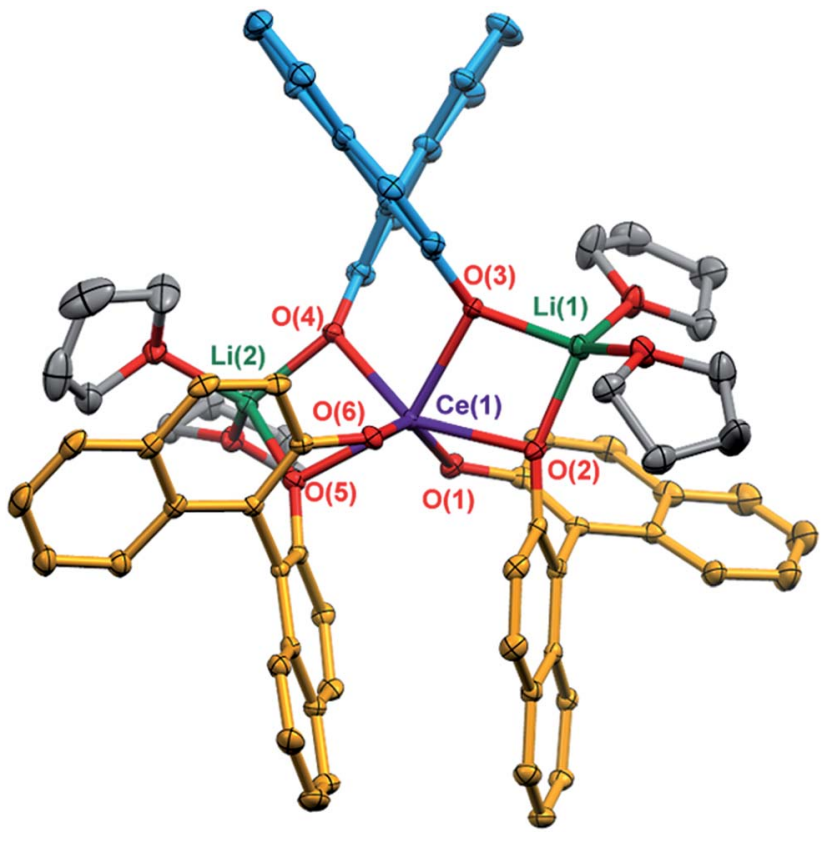

Fig. 8 Thermal ellipsoid plot of 2-Ce(het) shown at 30\% probability. The BINOLate ligands have been colored blue and orange to indicate the $S S / R R$ and $R / S$ fragments respectively. One interstitial molecule of THF has been removed for clarity. Selected bond distances $(\AA)$ : $\mathrm{Ce}(1)-$ $\mathrm{O}(1)$ 2.2685(17), $\mathrm{Ce}(1)-\mathrm{O}(2)$ 2.1958(18), $\mathrm{Ce}(1)-\mathrm{O}(3)$ 2.2709(18), $\mathrm{Ce}(1)-$ $\mathrm{O}(4)$ 2.2773(17), $\mathrm{Ce}(1)-\mathrm{O}(5)$ 2.1755(18), Ce(1)-O(6) 2.2917(17), Li(1)$\mathrm{O}(1)$ 1.921(5), $\mathrm{Li}(1)-\mathrm{O}(3)$ 1.954(5), $\mathrm{Li}(2)-\mathrm{O}(4)$ 1.960(5), $\mathrm{Li}(2)-\mathrm{O}(6)$ $1.913(5)$.

$\mathrm{mV})$. At low scan rates preferential oxidation of 1-Ce(het) could be achieved; however, the reduction current $\left(I_{\mathrm{pc}}\right)$ for the electrochemically generated $\mathrm{Ce}^{\mathrm{IV}}$ complexes display similar ratios across the scan rates investigated (Fig. 7, inset of $I_{\mathrm{pc}}(1) v s$. (2)). This suggests that BINOLate exchange occurs quickly on the CV collection time scale, and is consistent with our observations regarding facile BINOLate exchange in solution in our NMR studies. The two distinct redox events characterized for 1Ce(het) and 1-Ce(homo) coupled with the different coordination numbers supported at the respective Ce cations provided an opportunity to directly compare the complexes' electrochemical properties and their chemical oxidation reactivities.

Chemical oxidation of 1-Ce(het)/1-Ce(homo). Addition of 1 equiv. trityl chloride to THF solutions of 1-Ce(het) ( $0 \%$ ee), resulted in an immediate color change from orange to dark purple, where the formation of a diamagnetic heterobimetallic complex was supported by ${ }^{1} \mathrm{H}-,{ }^{7} \mathrm{Li}-$, and ${ }^{13} \mathrm{C}\left\{{ }^{1} \mathrm{H}\right\}$ NMR spectroscopies. Crystallization of the crude residue from concentrated THF solutions layered with pentane $(1: 4 \mathrm{v} / \mathrm{v})$ led to the isolation of an analytically pure product in $97 \%$ yield. X-ray diffraction studies confirmed the identity of the oxidation product as $\left[\mathrm{Li}_{2}(\mathrm{THF})_{4}\right]\left[(\mathrm{BINOLate})_{3} \mathrm{Ce}\right] \cdot 1 / 2\left(\mathrm{C}_{5} \mathrm{H}_{12}\right)$ (2-Ce(het)), the product of salt-elimination (Fig. 8 and Scheme 4).

Unlike the salt-elimination products of the heavier alkali metal homochiral frameworks ( $\mathrm{M}=\mathrm{Na}, \mathrm{K}, \mathrm{Cs}), \mathbf{2 - C e}($ het $)$ did not undergo a large structural rearrangement (Scheme 4, (rac)-2Ce(het) versus (rac)-2-Ce(het-axial)). The primary coordination 


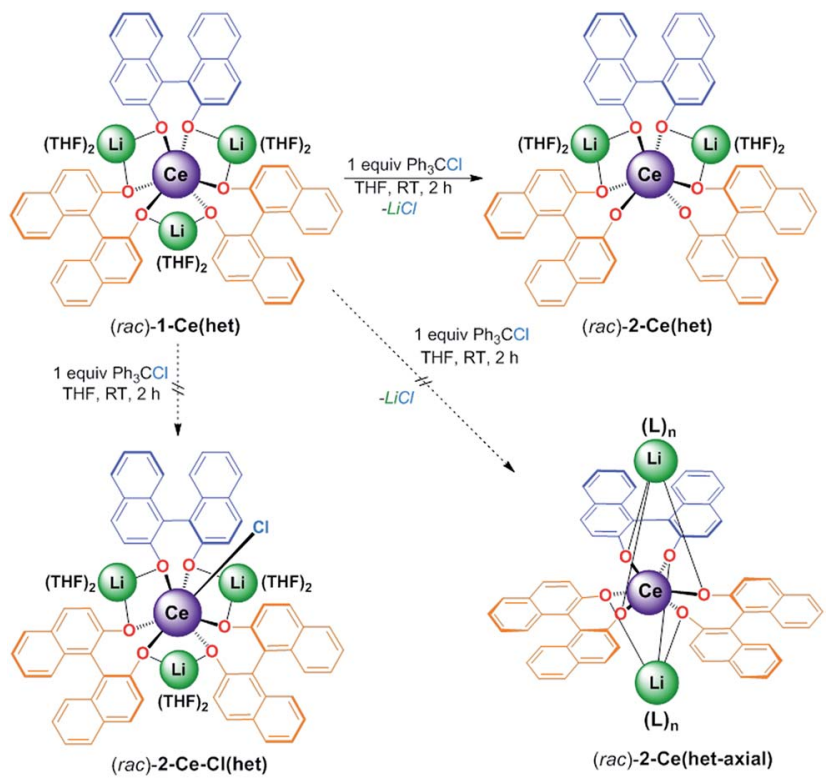

Scheme 4 Oxidation of 1-Ce(het) with $\mathrm{Ph}_{3} \mathrm{CCl}$ to produce salt-elimination product, $2-\mathrm{Ce}$ (het). Other previously observed oxidation products in the CeMB framework such as oxidative functionalization, (rac)-2-Ce-Cl(het), and $\mathrm{M}^{+}$axially capped salt-elimination products, (rac)-2-Ce(het-axial), were not observed.

sphere of 2-Ce(het) was composed of anionic BINOLate oxygens arranged in a distorted trigonal prismatic geometry. The $\mathrm{Li}^{+}$ cations remained bridging in a pseudo-equatorial fashion between BINOLate ligands rather than migrating to axially cap the tris(BINOLate) framework, as was the case for homochiral $\mathrm{Ce}^{\mathrm{IV}} / \mathrm{M}(\mathrm{M}=\mathrm{Na}, \mathrm{K})$ frameworks. ${ }^{7}$ The preference for the heterochiral diastereomer was maintained for 2-Ce(het) due to the smaller ionic radius of the $\mathrm{Ce}^{\mathrm{IV}}$ cation, while the conformation of the heterochiral BINOLate ligands disfavored axial $\mathrm{Li}-$ $\mathrm{O}_{\text {BINOLate }}$ coordination. Ce- $\mathrm{O}_{\text {BINOLate }}$ and $\mathrm{Li}-\mathrm{O}_{\text {BINOLate }}$ bond distances for 2-Ce(het) were similar to the previously reported $\mathrm{Ce}^{\mathrm{IV}}$ terminal and bridging aryloxides in the Ce/Li framework, and supported the $\mathrm{Ce}^{\mathrm{IV}}$ oxidation-state assignment. ${ }^{7 a, 19}$ Additional support for the $\mathrm{Ce}^{\mathrm{IV}}$ oxidation state was provided by cyclic voltammetry, which displayed clear metal-based reduction features (Fig. S18 $\dagger$ ).

Formation of 2-Ce(het) was surprising, as previous chemical oxidation studies of 1-Ce(homo) revealed an exclusive preference for oxidative functionalization over salt-elimination (Scheme 4, (rac)-2-Ce-Cl(het)). ${ }^{7,19}$ In those studies we demonstrated that the accessibility of the $\mathrm{Ce}^{\mathrm{III}}$ cation, which was governed by the main group metal ( $\mathrm{Li}, \mathrm{Na}$, or $\mathrm{K}$ ), controlled the rate of inner-sphere oxidation with trityl chloride. The ability of the $\mathrm{Ce}^{\mathrm{IV}}$ complex to reorganize and maintain a seven-coordinate geometry, however, appeared to dictate the selectivity of oxidative functionalization versus salt elimination. We observed that 1-Ce(homo) showed the highest level of reactivity with trityl chloride and formed only oxidative functionalized products (Scheme 5, and 2-Ce-Cl(homo)). In contrast, other Ce/M complexes ( $\mathrm{M}=\mathrm{Na}, \mathrm{K}, \mathrm{Cs})$ exhibited slower chemical oxidation with trityl chloride and formed salt-elimination products.



Scheme 5 Proposed mechanism and ligand exchange processes for the oxidation reaction of 1-Ce(het). Dashed equilibria are exchange pathways that have not been directly measured, but likely can occur under reaction conditions. 
Chemical oxidation - rate studies. While both 1-Ce(het) and 1-Ce(homo) are $\mathrm{Ce} / \mathrm{Li}$ heterobimetallic frameworks, the $\mathrm{Ce}^{\mathrm{III}}$ cation in 1-Ce(het) is more like that of 1-Ce(homo) in the heavier alkali metal congeners $(\mathrm{M}=\mathrm{Na}, \mathrm{K}, \mathrm{Cs})$. The six-coordinate 1-Ce(het) is much less accessible to interaction with solvent at the $\mathrm{Ce}^{\mathrm{III}}$ cation, due to the smaller binding site at $\mathrm{Ce}^{\mathrm{III}}$ with the heterochiral arrangement of the BINOLate ligands. Given the distinct differences in $\mathrm{Ce}^{\mathrm{III}}$ cation accessibility in the two readily exchanging diastereomers, we hypothesized that the expected reactivity differences between 1-Ce(het) and 1Ce(homo) towards inner-sphere chemical oxidation might readily be distinguished using chemical oxidation rate studies.

Rate studies were performed for 1-Ce with varying optical purities under pseudo-first order conditions using a 10-fold excess of trityl chloride (Fig. 9). The initial concentration of 1Ce(het) and 1-Ce(homo) were independently confirmed for each sample using ${ }^{7}$ Li-NMR (Table S2 $\dagger$ ). Oxidation of 1-Ce with trityl chloride was monitored by UV-Vis absorption spectroscopy following the growth of the characteristic ligand to metal charge transfer (LMCT) band at $487 \mathrm{~nm}$ in the Ce(Iv) products 2Ce(homo) and 2-Ce(het). ${ }^{7,19,20}$

Increased optical purity of 1-Ce resulted in increased rates of chemical oxidation $\left(k_{\text {obs}}\right)$, where a $\sim 5$ fold rate enhancement was observed by employing optically pure 1-Ce(homo) rather than racemic 1-Ce (3.37 versus $0.713 \mathrm{~s}^{-1}$; Fig. 9, traces $\mathrm{F}$ and $\mathrm{A}$ ). Values of $k_{\text {obs }}$ did not agree with an outer sphere mechanism, where it would be expected that 1-Ce(het) would undergo oxidation at a faster rate due to the more facile oxidation of 1Ce(het) than 1-Ce(homo). Instead, a first order dependence was observed for the initial concentration of 1-Ce(homo) in solution (Fig. 9, inset), and is consistent with an inner sphere oxidation mechanism involving 1-Ce(homo) in the rate determining step. ${ }^{7}$

Similar to our studies investigating the impact of $\mathrm{M}^{+}$on the kinetics of chemical oxidation with trityl chloride, ${ }^{7} k_{\text {obs }}$ for 1-Ce

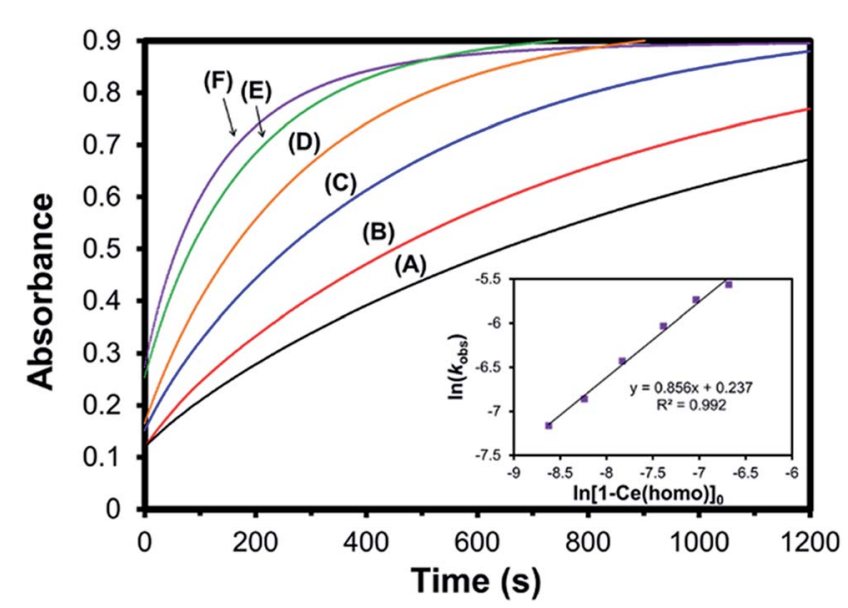

Fig. 9 Kinetic profile of $1-\mathrm{Ce}$ (het) $/ 1-\mathrm{Ce}$ (homo) $+\mathrm{Ph}_{3} \mathrm{CCl}$ in THF under pseudo-first order conditions (10 equiv. $\mathrm{Ph}_{3} \mathrm{Cl} ;[1-\mathrm{Ce}]=1.26 \mathrm{mM}$ ) at different optical purities of $1-\mathrm{Ce}$. (A) $0 \%$ ee (black trace), (B) $20 \%$ ee (red trace), (C) $40 \%$ ee (blue trace), (D) $60 \%$ ee (orange trace), (E) $80 \%$ ee (green trace), and (F) 100\% ee (purple trace). Inset shows $\ln \left(k_{\text {obs }}\right)$ versus the $\ln [1-\mathrm{Ce}(\text { homo })]_{0}$ in solution, confirming a first order relationship of 1-Ce(homo) on observed oxidation rate. followed the ability of the $\mathrm{Ce}^{\mathrm{III}}$ cation to adopt a seven-coordinate geometry rather than the thermodynamics or kinetics associated with an outer sphere electron transfer process. The configuration of the $R R S / S S R$ BINOLate fragments disfavor ligand reorganization in 1-Ce(het) to bind an additional ligand and achieve a seven-coordinate geometry. As a result, the chemical oxidation of 1-Ce(het) proceeds much slower than that of 1-Ce(homo). Given the rapid chemical oxidation rates and the observation that ligand redistribution/exchange is facile at RT in solution between 1-Ce(het) and 1-Ce(homo), we propose that the chemical oxidation reaction proceeds through the higher energy, but more reactive diastereomer, 1-Ce(homo) (Scheme 5).

Chemical oxidation - ligand exchange and proposed mechanism. If chemical oxidation of 1-Ce were to proceed through 1Ce(homo) the generation of the transient encounter complex, (rac)-1-Ce(homo)Cl-CPh $\mathbf{C P}_{3}$, would occur from ( $\mathrm{rac}$ )-1-Ce(homo) after dissociation of THF and coordination of trityl chloride (Scheme 5). As a consequence, oxidation of (rac)-1-Ce(homo)Cl$\mathbf{C P h}_{3}$ would initially form the oxidative functionalization product, $\quad\left[\mathrm{Li}_{3}(\mathrm{THF})_{5}\right]\left[(\mathrm{BINOLate})_{3} \mathrm{Ce}-\mathrm{Cl}\right] \quad$ (2-Ce-Cl(homo)), however, elimination of LiCl from 2-Ce-Cl(homo) synthesized from $(S)$-BINOL has not been observed. ${ }^{7}$ Since salt-elimination does not spontaneously occur with optically pure 2-Ce-Cl, it appeared that this reaction pathway was promoted by having both $(R R R)$ and $(S S S)$ 2-Ce-Cl(homo) present. We hypothesized that a ligand redistribution step between enantiomers $(R R R)-2$ Ce-Cl(homo) and (SSS)-2-Ce-Cl(homo) facilitated the key irreversible step to eliminate $\mathrm{LiCl}$ and form the observed product, 2$\mathrm{Ce}($ het).

To test the feasibility of the ligand redistribution step, both the $S S S$ and $R R R$ enantiomers of 2-Ce-Cl(homo) were independently synthesized and then mixed in equimolar quantities in THF- $d_{8}$ (Fig. 10). Immediate ligand redistribution was observed, where the ${ }^{1} \mathrm{H}$ - and ${ }^{7} \mathrm{Li}$-NMR spectra matched those of 2-Ce(het) in the presence of LiCl (Fig. 10D). Given these observations, we propose that intermolecular BINOLate ligand redistribution of 2-Ce-Cl(homo) would generate (rac)-2-Ce-Cl(het). As the larger

(A)

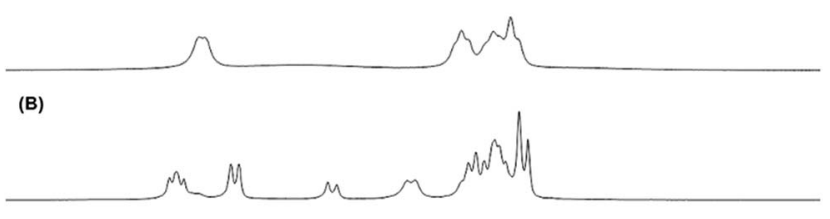

(c)

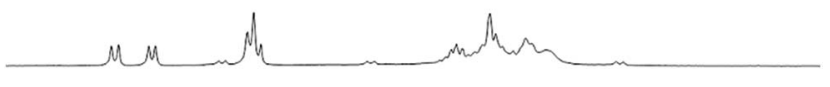

(D)

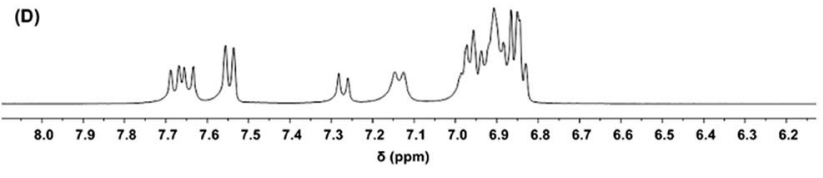

Fig. $10{ }^{1} \mathrm{H}-\mathrm{NMR}\left(400 \mathrm{MHz}, \mathrm{THF}-d_{8}\right)$ spectra of (A) (RRR)-2-Ce-Cl, (B) $(R R R)-2-\mathrm{Ce}-\mathrm{Cl}(19.3 \mathrm{mM})+(\mathrm{SSS})-2-\mathrm{Ce}-\mathrm{Cl}(21.2 \mathrm{mM}),(\mathrm{C})$ 2-Ce(het), and (D) $2-\mathrm{Ce}$ (het) +1 equiv. $\mathrm{LiCl}$. 
$\mathrm{Ce}^{\mathrm{III}}$ cation in 1-Ce(het) only adopted a six-coordinate geometry, it is likely that the $\mathrm{Cl}^{-}$ligand would be dissociated as an outer sphere counterion for the smaller $\mathrm{Ce}^{\mathrm{IV}}$ cation in $\mathbf{2}$-Ce-Cl(het). Salt-elimination of $\mathrm{LiCl}$ would then readily occur, producing 2$\mathbf{C e}(\mathbf{h e t})$. The thermodynamic preference of the $\mathrm{Ce}^{\mathrm{IV}}$ cation for the heterochiral diastereomer is likely associated with the size of the ion, as the smaller $\mathrm{RE}^{\mathrm{III}}$ cations, $\mathrm{Yb}^{\mathrm{III}}$ and $\mathrm{Y}^{\mathrm{III}}$, have similar ionic radii to $\mathrm{Ce}^{\mathrm{IV}}(0.900$ and 0.870 versus $0.868 \AA$ respectively $)^{\mathbf{1 3}}$ and also prefer the heterochiral diastereomer. ${ }^{\mathbf{1 0 , 1 2}}$

Our proposed mechanism accounts for both the unique kinetics and product selectivity observed in the chemical oxidation of (rac)-1-Ce(het)/1-Ce(homo) (Scheme 5). Ligand reorganization and cation accessibility to Lewis base coordination dictate the rate of inner-sphere chemical oxidation, which occurs through the faster reacting diastereomer, (rac)-1$\mathbf{C e}($ homo). Oxidation will lead to the formation of ( $\mathrm{rac}$ )-2-CeCl(homo); however, we have demonstrated that enantiomers of (rac)-2-Ce-Cl(homo) readily participate in ligand redistribution and undergo salt-elimination to form ( $\mathrm{rac}$ )-2-Ce(het). ${ }^{21}$ We have shown that while ligand reorganization controls the kinetics of the oxidation process, ligand redistribution is responsible for the observed product selectivity. Rapid ligand redistribution allows equilibration between kinetic and thermodynamic products, and facilitates the ultimate formation of the observed thermodynamic product.

The key findings of our mechanistic studies help address observed oxidative reactivity preferences of $\mathrm{Ce}^{\mathrm{III}}$ in various ligand frameworks towards ligand redistribution. For example, the simple homoleptic amides, $\mathrm{Ce}^{\mathrm{III}}\left(\mathrm{NR}_{2}\right)_{3} \quad\left(\mathrm{R}=\mathrm{Cy}{ }^{{ }^{\boldsymbol{b}} \boldsymbol{b}}\right.$ $\left.\mathrm{SiHMe}_{2},{ }^{5 \boldsymbol{a}, 22} \mathrm{SiMe}_{3}{ }^{5 \boldsymbol{c}, \boldsymbol{s} \boldsymbol{d}, \mathbf{2 3}}\right)$ display strikingly different oxidation chemistry with only subtle changes in ligand sterics. Similar to 1-Ce(homo), the Ce ${ }^{\mathrm{III}}$ cations in $\mathrm{Ce}^{\mathrm{III}}\left(\mathrm{NR}_{2}\right)_{3}$ are accessible to the coordination of an additional ligand; however the identity of the ultimate isolated product depends on the thermodynamics associated with a redistributed product.

In the case of the bulkier $\mathrm{SiMe}_{3}$ substituents, binding a fourth equivalent of $\mathrm{NR}_{2}$ is disfavored, leading to oxidative functionalized products $\mathrm{Ce}^{\mathrm{IV}}\left[\mathrm{N}\left(\mathrm{SiMe}_{3}\right)_{2}\right]_{3} \mathrm{X}$ over the redistributed homoleptic amide $\mathrm{Ce}^{\mathrm{IV}}\left[\mathrm{N}\left(\mathrm{SiMe}_{3}\right)_{2}\right]_{4}$. Alternatively, with slightly smaller R groups, $\mathrm{R}=\mathrm{Cy}$ and $\mathrm{SiHMe}_{2}$, a fourth amide will readily bind to a trivalent or tetravalent cerium cation. ${ }^{5 a, 9 b, 22}$ Similar to 1-Ce(homo)/1-Ce(het), $\mathrm{Ce}\left[\left(\mathrm{NR}_{2}\right)\right]_{3} \mathrm{X}$ may form during the course of the reaction when $\mathrm{R}=\mathrm{Cy}$ and $\mathrm{SiHMe}_{2}$; however, the redistributed product, $\mathrm{Ce}^{\mathrm{IV}}\left(\mathrm{NR}_{2}\right)_{4}$, is ultimately favored. This is due to increased stabilization by the more electron-rich ligand group, which was also seen for 1-Ce(homo)/1-Ce(het). In addition to heterobimetallic complexes such as 1-Ce(homo), tripodal frameworks ${ }^{\mathbf{8 a}, 24}$ show great promise towards minimizing ligand reorganization (i.e. increased accessibility of the $\mathrm{Ce}^{\mathrm{III}}$ cation), while minimizing the favorability of redistributed products.

\section{Conclusion}

In summary, we have delineated the roles of ligand reorganization $^{7,8}$ and redistribution processes ${ }^{5 a, c, 8 b, 9}$ in the observed oxidation chemistry of $\mathrm{Ce}^{\mathrm{III}}$ complexes. Synthesis and characterization of the heterochiral Ce/Li REMB complex, 1$\mathbf{C e}(\mathbf{h e t})$, was achieved. In the solid state, formation of the heterochiral diastereomer, 1-Ce(het), was exclusively preferred, whereas in solution a mixture of 1-Ce(het) and 1-Ce(homo) existed. Rapid exchange of the BINOLate ligands and Li cations between the two diastereomers was observed, and the thermodynamic preference for diastereomeric forms could be manipulated by choice of coordinating solvent. Electrochemical studies indicated that the $\mathrm{Ce}^{\mathrm{III} / \mathrm{IV}}$ redox couple for 1-Ce(het) was more accessible than 1-Ce(homo) by $\sim 250 \mathrm{mV}$. Despite the increased driving force, chemical oxidations using trityl chloride revealed that $\mathbf{1 - C e ( h o m o )}$ is oxidized more rapidly than 1Ce(het). Furthermore, $k_{\text {obs }}$ displayed a linear dependence on the concentration of 1-Ce(homo). Similar to our previous studies on ligand reorganization, the oxidation occurred through the most accessible $\mathrm{Ce}^{\mathrm{III}}$ ion and not the one with the most accessible $\mathrm{Ce}^{\mathrm{III} / \mathrm{IV}}$ couple.

Ligand exchange and redistribution processes were found to be directly responsible for product selectivity. Even though ligand reorganization facilitated rapid oxidation from the higher energy diastereomer, 1-Ce(homo), to yield the oxidative functionalization product, 2-Ce-Cl(homo), subsequent ligand redistribution processes resulted in the exclusive formation of the salt-eliminated product, 2-Ce(het) (Scheme 5). The reactivity of 1-Ce can mirror that of other $\mathrm{Ce}^{\mathrm{III}}$ frameworks that are prone to ligand redistribution, where subtle changes in ligand sterics can lead to dramatically different oxidation outcomes.

Even in systems where ligand reorganization can be controlled, active approaches to minimize ligand redistribution are needed to facilitate more predictable reaction outcomes. One approach would be to alter the thermodynamics of ligand redistribution pathways by minimizing specific conformational possibilities with a particular supporting ligand framework, such as chiral ligands or constrained tripodal frameworks. We believe that heterobimetallic complexes should continue to be useful Ce ${ }^{\mathrm{III}}$ starting materials, as salt-elimination can serve as a suitable driving force, while "-ate" complex formation readily occurs with a number of ligand frameworks.

\section{Acknowledgements}

E. J. S. and P. J. W. acknowledge the University of Pennsylvania and the U.S. NSF (CHE-1026553 and CHE-0840438 for an X-ray diffractometer) for financial support of this work.

\section{Notes and references}

1 D. T. Richens, The Chemistry of Aqua Ions: Synthesis, Structure, and Reactivity, John Wiley \& Sons, New York, 1997. 2 (a) M. Shibasaki, H. Sasai and T. Arai, Angew. Chem., Int. Ed. Engl., 1997, 36, 1236-1256; (b) M. Shibasaki and N. Yoshikawa, Chem. Rev., 2002, 102, 2187-2209; (c) J.-C. G. Bünzli and C. Piguet, Chem. Rev., 2002, 102, 18971928; (d) H. C. Aspinall, Chem. Rev., 2002, 102, 1807-1850; (e) D. Parker, R. S. Dickins, H. Puschmann, C. Crossland and J. A. K. Howard, Chem. Rev., 2002, 102, 1977-2010; (f) Y. Horiuchi, V. Gnanadesikan, T. Ohshima, H. Masu, 
K. Katagiri, Y. Sei, K. Yamaguchi and M. Shibasaki, Chem.Eur. J., 2005, 11, 5195-5204; (g) S.-y. Tosaki, R. Tsuji, T. Ohshima and M. Shibasaki, J. Am. Chem. Soc., 2005, 127, 2147-2155; (h) J. Andrews and A.-S. Chauvin, Lanthanides: Luminescence Applications, in The Rare Earth Elements Fundamentals and Applications, ed. D. A. Atwood, John Wiley \& Sons, Chichester, West Sussex, UK, 2012, pp. 135152; ( $i$ ) Y. Mori and S. Kobayashi, Organic Synthesis, in The Rare Earth Elements Fundamentals and Applications, ed. D. A. Atwood, John Wiley \& Sons, Chichester, West Sussex, UK, 2012, pp. 437-458; (j) Y. Yao and K. Nie, Homogeneous Catalysis, in The Rare Earth Elements Fundamentals and Applications, ed. D. A. Atwood, John Wiley \& Sons, Chichester, West Sussex, UK, 2012, p. 475; (k) C. F. G. C. Geraldes, Lanthanide Shift Reagents, in The Rare Earth Elements Fundamentals and Applications, ed. D. A. Atwood, John Wiley \& Sons, Chichester, West Sussex, UK, 2012, pp. 501-520; (l) S. Laurent, L. V. Elst, S. Boutry and R. N. Nuller, Lanthanides: Magnetic Resonance Imaging, in The Rare Earth Elements Fundamentals and Applications, ed. D. A. Atwood, John Wiley \& Sons, Chichester, West Sussex, UK, 2012, pp. 521-534; $(\mathrm{m})$ A.-S. Chauvin, Luminescent Bioprobes, in The Rare Earth Elements Fundamentals and Applications, ed. D. A. Atwood, John Wiley \& Sons, Chichester, West Sussex, UK, 2012, pp. 535-560.

3 (a) E. Pershagen and K. E. Borbas, Coord. Chem. Rev., 2014, 273-274, 30-46; (b) J.-C. G. Bünzli, J. Coord. Chem., 2014, 67, 3706-3733; (c) P. Caravan, J. J. Ellison, T. J. McMurry and R. B. Lauffer, Chem. Rev., 1999, 99, 2293-2352; (d) A. D. Sherry, P. Caravan and R. E. Lenkinski, J. Magn. Reson. Imag., 2009, 30, 1240-1248; (e) J.-M. Idée, M. Port, C. Robic, C. Medina, M. Sabatou and C. Corot, J. Magn. Reson. Imag., 2009, 30, 1249-1258; (f) S. Viswanathan, Z. Kovacs, K. N. Green, S. J. Ratnakar and A. D. Sherry, Chem. Rev., 2010, 110, 2960-3018; (g) K. N. Green, S. Viswanathan, F. A. Rojas-Quijano, Z. Kovacs and A. D. Sherry, Inorg. Chem., 2011, 50, 1648-1655; (h) W. T. K. Chan and W.-T. Wong, Polyhedron, 2014, 83, 150158.

4 (a) H. C. Aspinall, Chemistry of the f-block Elements, Overseas Publishing Company, UK, 2001, vol. 1; (b) S. A. Cotton and J. M. Harrowfield, Lanthanides: Coordination Chemistry, in The Rare Earth Elements: Fundamentals and Applications, ed. D. A. Atwood, John Wiley \& Sons, Chichester, West Sussex, UK, 2012; (c) S. Cotton, Lanthanide and Actinide Chemistry, John Wiley \& Sons Ltd, West Sussex, England, 2006.

5 (a) A. R. Crozier, A. M. Bienfait, C. Maichle-Mossmer, K. W. Tornroos and R. Anwander, Chem. Commun., 2013, 49, 87-89; (b) P. B. Hitchcock, Q. G. Huang, M. F. Lappert and X. H. Wei, J. Mater. Chem., 2004, 14, 3266-3273; (c) P. B. Hitchcock, A. G. Hulkes and M. F. Lappert, Inorg. Chem., 2004, 43, 1031-1038; (d) O. Eisenstein, P. B. Hitchcock, A. G. Hulkes, M. F. Lappert and L. Maron, Chem. Commun., 2001, 1560-1561; (e) N. A. Piro,
J. R. Robinson, P. J. Walsh and E. J. Schelter, Coord. Chem. Rev., 2014, 260, 21-36.

6 (a) G. A. Molander, Chem. Rev., 1992, 92, 29-68; (b) V. Nair, L. Balagopal, R. Rajan and J. Mathew, Acc. Chem. Res., 2004, 37, 21-30; (c) T. L. Ho, Synthesis, 1973, 347-354; (d) T. Imamoto, Y. Koide and S. Hiyama, Chem. Lett., 1990, 1445-1446; (e) A. K. Das, Coord. Chem. Rev., 2001, 213, 307325; $(f)$ N. G. Connelly and W. E. Geiger, Chem. Rev., 1996, 96, 877-910; $(g)$ W. Rüttinger and G. C. Dismukes, Chem. Rev., 1997, 97, 1-24; (h) J. L. Fillol, Z. Codola, I. GarciaBosch, L. Gomez, J. J. Pla and M. Costas, Nat. Chem., 2011, 3, 807-813; (i) W. C. Ellis, N. D. McDaniel, S. Bernhard and T. J. Collins, J. Am. Chem. Soc., 2010, 132, 10990-10991; (j) R. Tagore, H. Y. Chen, H. Zhang, R. H. Crabtree and G. W. Brudvig, Inorg. Chim. Acta, 2007, 360, 2983-2989; (k) S. W. Gersten, G. J. Samuels and T. J. Meyer, J. Am. Chem. Soc., 1982, 104, 4029-4030; (l) T. Kreuzer, E. S. Lox, D. Lindner and J. Leyrer, Catal. Today, 1996, 29, 17-27; (m) H. Inaba and H. Tagawa, Solid State Ionics, 1996, 83, 1-16; (n) A. Trovarelli, Catal. Rev., 1996, 38, 439-520; (o) A. Trovarelli, C. de Leitenburg, M. Boaro and G. Dolcetti, Catal. Today, 1999, 50, 353-367; (p) A. Trovarelli, Catalysis by Ceria and Related Materials, Imperial College Press, London, 2002.

7 (a) J. R. Robinson, Z. Gordon, C. H. Booth, P. J. Carroll, P. J. Walsh and E. J. Schelter, J. Am. Chem. Soc., 2013, 135, 19016-19024; (b) J. R. Robinson, P. J. Carroll, P. J. Walsh and E. J. Schelter, Angew. Chem., Int. Ed., 2012, 51, 1015910163.

8 (a) C. Morton, N. W. Alcock, M. R. Lees, I. J. Munslow, C. J. Sanders and P. Scott, J. Am. Chem. Soc., 1999, 121, 11255-11256; (b) I. J. Casely, S. T. Liddle, A. J. Blake, C. Wilson and P. L. Arnold, Chem. Commun., 2007, 50375039.

9 (a) M. DelaRosa, K. Bousman, J. Welch and P. Toscano, J. Coord. Chem., 2002, 55, 781-793; (b) P. B. Hitchcock, M. F. Lappert and A. V. Protchenko, Chem. Commun., 2006, 3546-3548; (c) M. Ciampolini, F. Mani and N. Nardi, Dalton Trans., 1977, 1325-1328; (d) F. M. A. Sroor and F. T. Edelmann, Tetravalent Chemistry: Organometallic, in The Rare Earth Elements: Fundamentals and Applications, D. A. Atwood, ed. John Wiley \& Sons, Chichester, West Sussex, UK, 2012, pp. 321-333; (e) J. A. Bogart, A. J. Lewis, S. A. Medling, N. A. Piro, P. J. Carroll, C. H. Booth and E. J. Schelter, Inorg. Chem., 2013, 52, 11600-11607; $(f)$ T. Behrsing, A. M. Bond, G. B. Deacon, C. M. Forsyth, M. Forsyth, K. J. Kamble, B. W. Skelton and A. H. White, Inorg. Chim. Acta, 2003, 352, 229-237; (g) D. Werner, G. B. Deacon, P. C. Junk and R. Anwander, Chem.-Eur. J., 2014, 20, 4426-4438; (h) G.-C. Wang, Y.-M. So, K.-L. Wong, K.-C. Au-Yeung, H. H. Y. Sung, I. D. Williams and W.-H. Leung, Chem.-Eur. J., 2015, 21, 16126-16135.

10 H. C. Aspinall, J. F. Bickley, J. L. M. Dwyer, N. Greeves, R. V. Kelly and A. Steiner, Organometallics, 2000, 19, 54165423.

11 (a) L. Di Bari, M. Lelli and P. Salvadori, Chem.-Eur. J., 2004, 10, 4594-4598; (b) L. Di Bari, M. Lelli, G. Pintacuda, 
G. Pescitelli, F. Marchetti and P. Salvadori, J. Am. Chem. Soc., 2003, 125, 5549-5558.

12 (a) N. Yamagiwa, H. B. Qin, S. Matsunaga and M. Shibasaki, J. Am. Chem. Soc., 2005, 127, 13419-13427; (b) N. Yamagiwa, S. Matsunaga and M. Shibasaki, Angew. Chem., Int. Ed., 2004, 43, 4493-4497.

13 R. D. Shannon, Acta Crystallogr., Sect. A: Found. Crystallogr., 1976, 32, 751-767.

14 (a) A. J. Wooten, P. J. Carroll and P. J. Walsh, Angew. Chem., Int. Ed., 2006, 45, 2549-2552; (b) A. J. Wooten, P. J. Carroll and P. J. Walsh, Org. Lett., 2007, 9, 3359-3362; (c) A. J. Wooten, P. J. Carroll and P. J. Walsh, J. Am. Chem. Soc., 2008, 130, 7407-7419.

15 (a) K. G. Orrell, Two-Dimensional Methods of Monitoring Exchange, in eMagRes, John Wiley \& Sons, Ltd, 2007; (b) C. L. Perrin and T. J. Dwyer, Chem. Rev., 1990, 90, 935-967; (c) J. Jeener, B. H. Meier, P. Bachmann and R. R. Ernst, J. Chem. Phys., 1979, 71, 4546-4553; (d) B. S. Brunschwig and N. Sutin, Coord. Chem. Rev., 1999, 187, 233-254.

16 (a) S. P. Babailov, Prog. Nucl. Magn. Reson. Spectrosc., 2008, 52, 1-21; (b) L. S. Cahill, R. P. Chapman, J. F. Britten and G. R. Goward, J. Phys. Chem. B, 2006, 110, 7171-7177; (c) A. Pastor and E. Martinez-Viviente, Coord. Chem. Rev., 2008, 252, 2314-2345; (d) A. P. Kalverda, J. Salgado, C. Dennison and G. W. Canters, Biochemistry, 1996, 35, 3085-3092; (e) S. Fischer, P. D. J. Grootenhuis, L. C. Groenen, W. P. Vanhoorn, F. Vanveggel, D. N. Reinhoudt and M. Karplus, J. Am. Chem. Soc., 1995, 117, 1611-1620; $(f)$ M. C. Chen, J. A. S. Roberts and T. J. Marks, J. Am. Chem. Soc., 2004, 126, 4605-4625; $(g)$ T. Brotin, A. Lesage, L. Emsley and A. Collet, J. Am. Chem. Soc., 2000, 122, 1171-1174; (h) L. Banci, I. Bertini, F. Briganti, C. Luchinat, A. Scozzafava and M. V. Oliver, Inorg. Chem., 1991, 30, 4517-4524; (i) F. A. Dunand, S. Aime and A. E. Merbach, J. Am. Chem. Soc., 2000, 122, 1506-1512; (j) S. Aime, M. Botta and G. Ermondi, Inorg. Chem., 1992, 31, 4291-4299; (k) R. Willem, Prog. Nucl.
Magn. Reson. Spectrosc., 1988, 20, 1-94; (l) J. D. Heise, D. Raftery, B. K. Breedlove, J. Washington and C. P. Kubiak, Organometallics, 1998, 17, 4461-4468; $(\mathrm{m})$ L. Di Bari, S. Di Pietro, G. Pescitelli, F. Tur, J. Mansilla and J. M. Saá, Chem.-Eur. J., 2010, 16, 14190-14201.

17 J. R. Robinson, J. Gu, P. J. Carroll, E. J. Schelter and P. J. Walsh, J. Am. Chem. Soc., 2015, 137, 7135-7144.

18 J. C. Cobas and M. Martin-Pastor, EXSYCalc, 1.0, Mestrelab Research, Santiago De Compostela.

19 J. R. Robinson, C. H. Booth, P. J. Carroll, P. J. Walsh and E. J. Schelter, Chem.-Eur. J., 2013, 19, 5996-6004.

20 Our proposed mechanism implies the formation of 2-Ce$\mathbf{C l}$ (homo) as an intermediate to the formation of 2-Ce(het). Although $\varepsilon$ values of the two compounds are within a $5 \%$ of one another at $487 \mathrm{~nm}\left(\varepsilon(2-\mathbf{C e}(\right.$ het $))=8691 \mathrm{M}^{-1} \mathrm{~cm}^{-1}$; $\varepsilon($ 2-Ce-Cl(homo) $)=8270 \mathrm{M}^{-1} \mathrm{~cm}^{-1}$ ), if 2-Ce-Cl(homo) were to build up during the rate studies an underestimation of $k_{\text {obs }}$ would occur. In the worst case scenario, which would assume that all of the $\mathrm{Ce}^{\mathrm{IV}}$ species in solution corresponded to 2 -Ce-Cl(homo), a $12 \%$ error in $k_{\text {obs }}$ would be expected.

21 It should be noted that exchange between the $\mathrm{Ce}^{\mathrm{IV}}$ product, (rac)-2-Ce(het), and the Ce $\mathrm{Ce}^{\mathrm{III}}$ starting materials, (rac)-1Ce(het) and ( $r a c)-1-C e(h o m o)$, cannot be excluded in our current proposal, given the ease of the ligand redistribution processes for (rac)-1-Ce and (rac)-2-Ce (Scheme 5).

22 U. J. Williams, D. Schneider, W. L. Dorfner, C. MaichleMossmer, P. J. Carroll, R. Anwander and E. J. Schelter, Dalton Trans., 2014, 43, 16197-16206.

23 (a) U. J. Williams, P. J. Carroll and E. J. Schelter, Inorg. Chem., 2014, 53, 6338-6345; (b) U. J. Williams, J. R. Robinson, A. J. Lewis, P. J. Carroll, P. J. Walsh and E. J. Schelter, Inorg. Chem., 2014, 53, 27-29.

24 J. A. Bogart, C. A. Lippincott, P. J. Carroll, C. H. Booth and E. J. Schelter, Chem.-Eur. J., 2015, 21, 17850-17859. 